\title{
The Peripheral Vascular Response to Severe Exercise in Untethered Dogs before and after Complete Heart Block
}

\author{
Stephen F. Vatner, Charles B. Higgins, Saxon White, \\ Thomas Patrick, and Dean Frankin with the technical assistance of \\ Dantel P. McKown \\ From the Department of Medicine, University of California, San Diego, and \\ Scripps Clinic and Research Foundation, La Jolla, California 92037
}

\begin{abstract}
A B S T RAC T The peripheral vascular response to severe exercise was studied in 11 healthy conscious dogs instrumented with Doppler ultrasonic flow probes on the mesenteric, renal, and iliac arteries, and miniature pressure gauges in the aorta. The response to severe exercise was restudied in six of these dogs after recovery from a second operation producing complete heart block by the injection of formalin into the atrioventricular (AV) node. Three of these dogs also exercised while their ventricles were paced at rates of $100 / \mathrm{min}$ and $200 / \mathrm{min}$. The untethered normal dogs ran at speeds of $15-25 \mathrm{miles} / \mathrm{hr}$ behind a mobile recording unit for a distance averaging 1.5 miles, while continuous measurements of arterial blood pressure and blood flow were telemetered and recorded on magnetic tape. Severe exercise in normal dogs increased heart rate from 84 to $259 / \mathrm{min}$, arterial pressure from 89 to $140 \mathrm{~mm} \mathrm{Hg}$, flow resistance in the mesenteric and renal beds by 59 and $52 \%$ respectively, and iliac blood flow $479 \%$ above control, while mesenteric and renal blood flows remained constant and iliac resistance decreased by $73 \%$.
\end{abstract}

In dogs with complete AV block, severe exercise at speeds of 10-18 miles/hr increased heart rate from 47 to $78 / \mathrm{min}$, mean arterial pressure from 81 to $89 \mathrm{~mm} \mathrm{Hg}$, iliac flow $224 \%$, resistance in the renal bed by $273 \%$, and mesenteric bed by $222 \%$ while it decreased blood flow in mesenteric and renal beds by 61 and $65 \%$ respectively, and iliac resistance by $62 \%$. A similar response occurred during exercise with pacing at $100 / \mathrm{min}$,

This work was presented in part before the 43rd Scientific Sessions of the American Heart Association in Atlantic City, N. J., November 1970.

Dr. Higgins is a Surgical Scholar supported by U. S. Public Health Service Grant GM 01559.

Dr. White was an Overseas Research Fellow of the Life Insurance Medical Research Fund of Australia and New Zealand.

Received for publication 7 January 1971 and in revised form 31 March 1971. but when paced at $200 /$ min a more normal exercise response reappeared. Thus, in normal dogs the peripheral vascular response to severe exercise involved increases in heart rate, arterial pressure and visceral resistance but visceral blood flow did not decrease. In dogs with heart block, where the ability to increase heart rate is severely compromised, compensatory reduction of mesenteric and renal blood flows occurred.

\section{INTRODUCTION}

The primary cardiovascular adjustment to severe exercise involves an increase in cardiac output to provide increased blood flow to the working muscles. In addition, the visceral vascular beds are thought to respond to severe exercise with sufficient increases in resistance to reduce blood flow in the mesenteric and renal circulations (1-8), thereby diverting blood flow from the inactive viscera to the exercising musculature. A1though this latter mechanism is teleologically appealing, direct measurements of regional blood flows in healthy conscious animals during exercise have indicated that this compensatory mechanism does not occur, i.e., blood flow to the kidney and gut do not decrease (9-11). However, it is conceivable that this peripheral mechanism is potentially available and although not apparent in the normal animals, could be revealed if the central adjustment to exercise were impaired, e.g., by preventing the increase in heart rate during exercise.

Accordingly, in the present investigation, 11 normal, healthy, untrained mongrel dogs were studied during severe exercise and 6 of these dogs were restudied during severe exercise when the increase in heart rate occurring normally during exercise was limited by the presence of surgically-induced complete heart block. In order to obtain a response to exercise free from the impediments of cables, tethers, treadmills, and the laboratory environment, measurements of blood flow and blood pressure

1950 The Journal of Clinical Investigation Volume 501971 


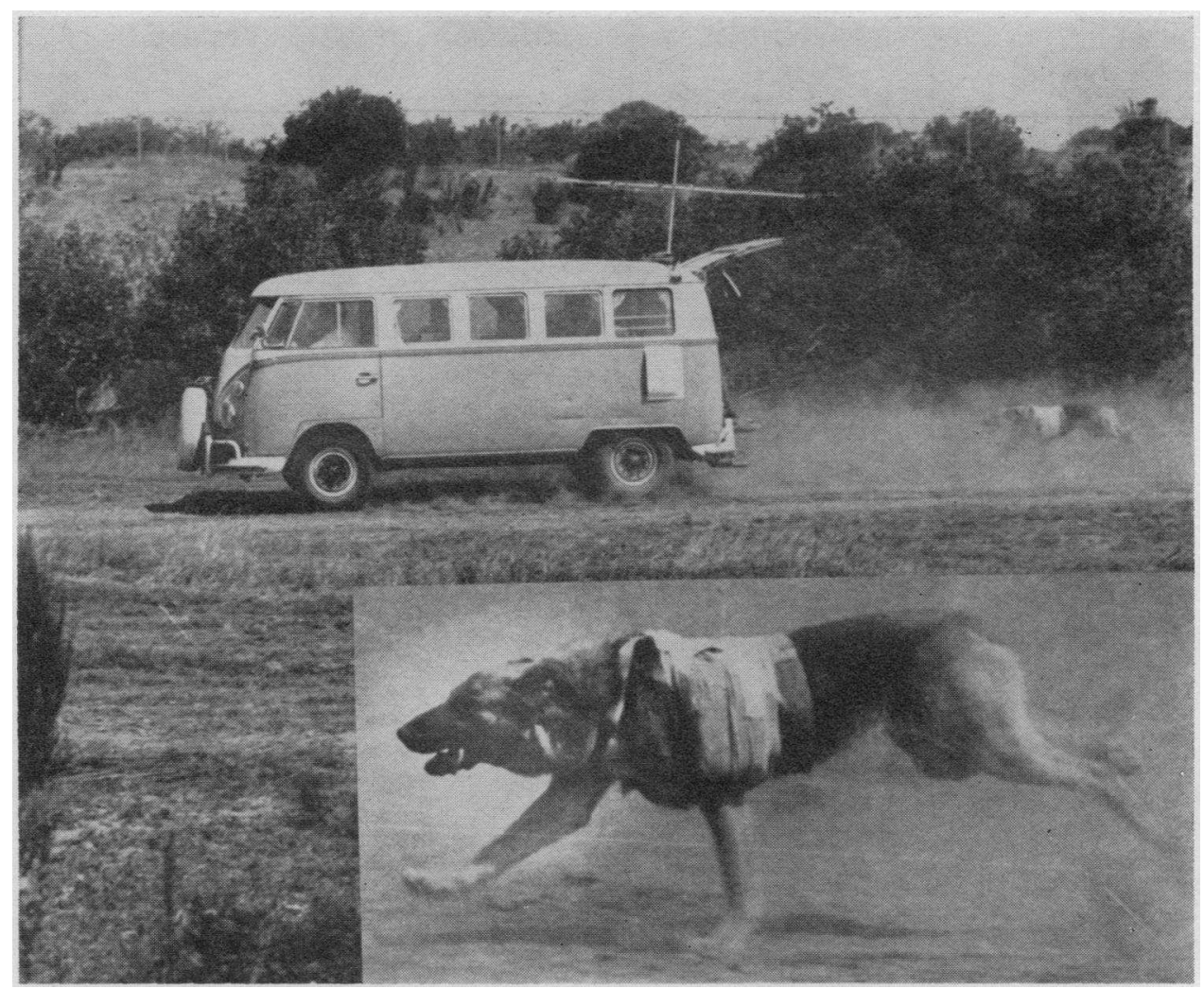

FIGURE 1 One of the instrumented dogs running at $22 \mathrm{miles} / \mathrm{hr}$ behind the mobile recording unit. The FM signal containing the flow-pressure data is telemetered from the instruments carried by the dog in saddlebags (insert) and received by the antenna on the bus, which in turn is coupled to the recording instruments.

were telemetered from the untethered dogs as they ran behind a mobile recording unit over level and graded terrain for distances averaging 1.5 miles and at speeds of 15-25 miles/hr. This study was designed first to elucidate the peripheral vascular response to severe exercise in the normal animal and specifically to determine the extent to which shunting of visceral flow occurred. In addition, we determined the peripheral circulatory adjustments to severe exercise when the central cardiac response, i.e., the increase in heart rate, was limited.

\section{METHODS}

Mongrel dogs weighing between 22 and $36 \mathrm{~kg}$ were operated upon using $\mathrm{Na}$ pentobarbital, $30 \mathrm{mg} / \mathrm{kg}$ and sterile surgical technique. Doppler ultrasonic blood-flow transducers (12) were implanted around the cranial mesenteric, left renal and left iliac arteries, and miniature pressure gauges ${ }^{1}$ (13) were implanted in the thoracic or abdominal aorta. Complete heart block was produced during a second operation using a right thoracotomy incision and $\mathrm{Na}$ pentobarbital anesthesia, 30 $\mathrm{mg} / \mathrm{kg}$. The atrioventricular (AV) node was destroyed by injection of $0.1-1.0 \mathrm{cc}$ of $37 \%$ formalin with a 23 gauge

\footnotetext{
${ }^{1}$ Konigsberg P22; Konigsberg Instruments, Inc, Pasadena,
}

needle positioned in the area of the AV node by palpation through the right atrium. Complete heart block was confirmed by electrocardiogram. Pacemaker electrodes fabricated from multistranded copper wire were sutured to the right ventricle during the latter operation. The dogs were paced during recovery using a Medtronic pacemaker.' On the first postoperative day, the pacemaker rate was turned down from $140 / \mathrm{min}$ to $100 / \mathrm{min}$ and kept there for $1-4 \mathrm{wk}$ until the dogs had recovered from the operation.

The experiments were conducted in 11 normal, healthy mongrel dogs 2-6 wk after recovery from implantation of blood flow probes and blood pressure gauges, and in 6 of these dogs 1-4 wk after recovery from the second operation at which complete heart block was induced. The protocol for the experiments was as follows. The dogs were taken to isolated roads and allowed to recline at rest while control records of blood flow and arterial pressure were recorded. The dogs were allowed to stand 1-3 min before exercise. Then the mobile unit carrying the electronic recording equipment drove off. The dogs ran behind the van at speeds of 15-25 miles/hr over level and graded roads for distances averaging 1.5 miles and ranging up to 6 miles (Fig. 1). Occasionally the dogs would stop briefly to urinate, or defecate, or chase a squirrel. The level of exercise attained by the dogs in heart block was slightly. lower, running at speeds of $10-18 \mathrm{miles} / \mathrm{hr}$. Two of these dogs exercised

\footnotetext{
${ }^{2}$ Medtronic, Inc. Minneapolis, Minn.
} 


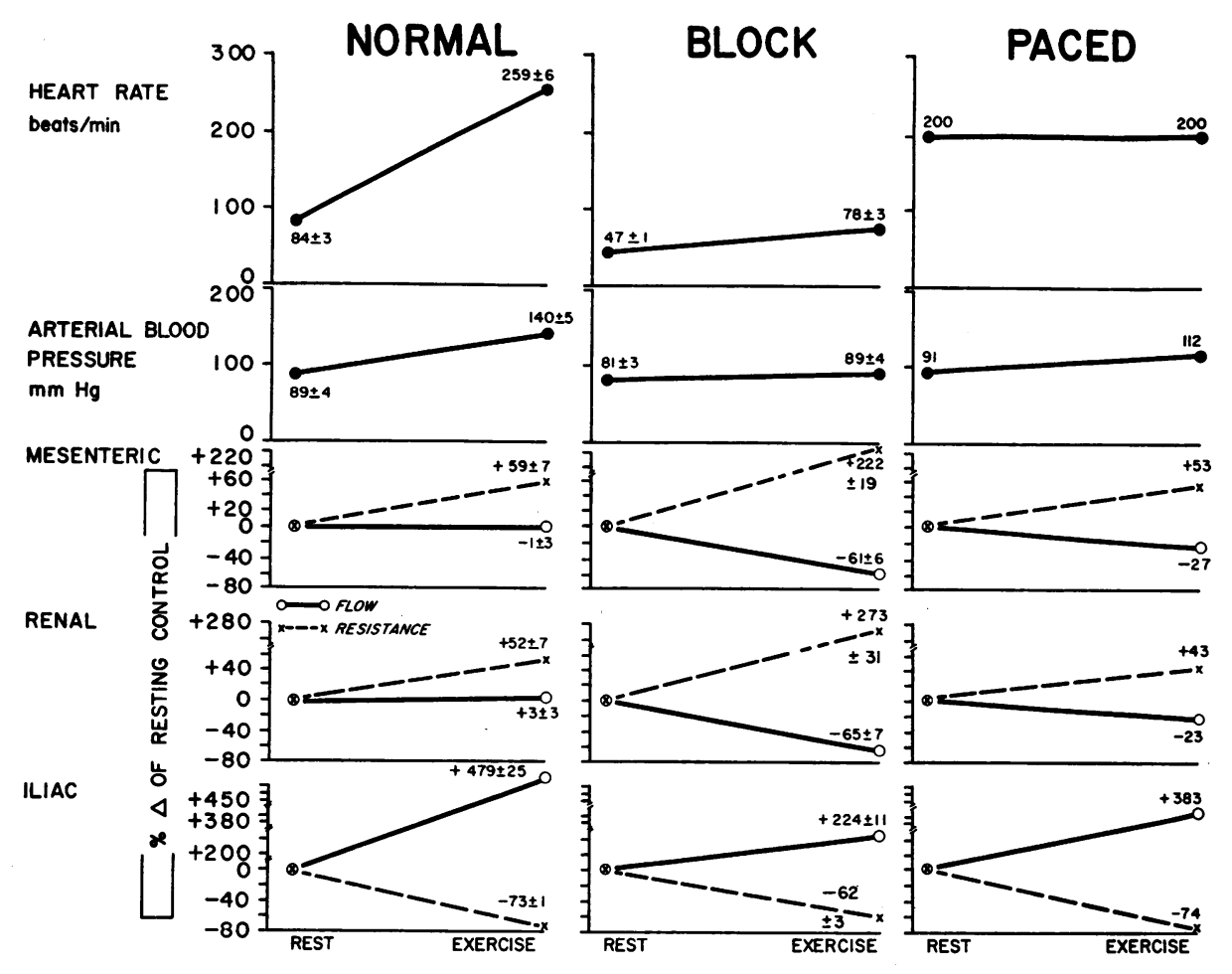

FIGURE 2 A comparison between rest and severe exercise of the average and SEM figures for heart rate in beats/min., mean arterial pressure in $\mathrm{mm} \mathrm{Hg}$, and flow and resistance in the mesenteric, renal, and iliac beds represented as per cent change from resting control. The solid lines with open circles represent flow and the broken lines with the " $\mathrm{X}$ " represent calculated mean vascular resistance. The panel at the left shows average responses of 11 normal dogs, the panel in the middle shows average responses of 6 heart block dogs, and the panel at the right shows average responses of 3 heart block dogs that exercised while being paced at $200 / \mathrm{min}$.

severely only if a rope leash was loosely attached to their harness and held by one of the investigators sitting in the van. The level of exercise attained in all dogs was considered to be severe since it required an average of $45 \mathrm{~min}$ to recover normal hemodynamics and respiratory rate. Three of the dogs with AV block exercised while being paced at ventricular rates of $100 / \mathrm{min}$ and $200 / \mathrm{min}$. The level of exercise of the dogs paced at $100 / \mathrm{min}$ was similar to that attained without pacing, whereas, the level of exercise attained by the dogs running while being paced at $200 / \mathrm{min}$ was similar to that which they reached when they were in sinus rhythm. The dogs were repeatedly studied several days or weeks later.

The electronic equipment carried by the animal (Fig. 2) consisted of a Doppler flow pressure, telemetry system which was powered by two $8.1 \mathrm{v}$ Mercury batteries (Mallory TR 236R; Mallory Battery Co.). The system, utilizing FM-FM modulation techniques, consisted of conventional ulltrasonic Doppler-flow velocity electronics (crystal exciter, and tuned radio frequency receiver) operating at an approximate frequency of $9 \mathrm{mHz}$, and a differential $\mathrm{DC}$ amplifier and voltage-controlled oscillator ${ }^{3}$ which converted the output of the miniature implantable arterial pressure gauge to a signal ranging in frequency from 37 to $43 \mathrm{kHz}$ in proportion to pressure.

\footnotetext{
${ }^{8}$ Circuit diagrams available from authors.
}

The flow signal with frequency components from $200 \mathrm{~Hz}$ to $15 \mathrm{kHz}$, was linearly summed with the voltage-controlled oscillator signal to form a frequency-multiplexed video signal. This signal was applied to the input of a frequencymodulated, radiofrequency transmitter operating in the 88$108 \mathrm{mHz}$ range. The power output, approximately $10 \mathrm{mw}$ coupled to a shortened, inductively-loaded stub antenna, was adequate to transmit the signals over a several hundred foot range to the mobile recording station (Fig. 1).

The mobile recording unit consisted of an FM communications receiver, subcarrier discriminator, signal processing electronics, and a tape recorder. A commercial 5 element FM antenna mounted on the roof of the van served to receive the telemetered signals from the animal. Power for the equipment was obtained from a DC to AC inverter (Heathkit model MP-14, Heathkit, Benton Harbor, Mich.) which was powered by a $12 \mathrm{v}$ automobile battery.

The FM tuner (Heathkit model AJ-15) was modified to disable the FM deemphasis network and multiplex circuitry, thus providing video response sufficient to recover both the Doppler flow signal $(200 \mathrm{~Hz}-15 \mathrm{kHz})$ and the $37-43 \mathrm{kHz}$ pressure-modulated subcarrier signal. The output of the FM tuner was processed by a $15 \mathrm{kHz}$ low-pass filter to extract the Doppler flow signal which was recorded on one channel of the tape recorder (Sony model TC560D Sony Superscope, Inc., Sun Valley, Calif.). The output of the tuner was also applied directly to the input of a subcarrier frequency dis- 
criminator (Airpax model FDS-30; Airpax Electronics Inc.) which converted the 37 to $43 \mathrm{kHz}$ frequency modulation signal to a DC voltage proportional to pressure. This voltage was applied to the input of a voltage-controlled oscillator having a frequency range of $8-18 \mathrm{kHz}$. The output of this voltage-controlled oscillator was summed with a voice signal from the microphone amplifier $(300 \mathrm{~Hz}-3 \mathrm{kHz})$ and applied to the remaining channel of the tape recorder.

The Doppler flow signal from the Sony tape recorder was processed by a Krohn-Hite variable frequency filter (model 315A ; Krohn-Hite Corp.) set to pass signals between 200 $\mathrm{Hz}$ and $20 \mathrm{kHz}$ and then by a frequency discriminator whose output is a DC voltage proportional to instantaneous Doppler frequency shift. Zero blood flow was repeatedly determined electrically and confirmed at the termination of the experiment. Volume flow calibrations in two dogs by means of timed collections of blood flow verified the linear relationship between velocity, as measured by the Doppler flowmeter, and volume blood flow (14). At autopsy, the flow transducers were found to be firmly adherent to the blood vessels through a fibrous scar which minimized changes in the cross sectional area of the vessel within the flow transducers. The pressure signal was coupled to a frequency discriminator ${ }^{3}$ which provided an output proportional to the instantaneous arterial pressure. The pressure gauges were calibrated in vivo against a Statham $\mathrm{P} 23 \mathrm{Db}$ strain gauge manometer.

The data were played back on a multichannel directwriting oscillograph. Mean arterial pressure and mean blood flows were derived from the phasic signals using electronic RC filters with a 2-sec time constant. Vascular bed resistance was computed by an analogue divider which provided a DC voltage proportional to the quotient of mean pressure and mean flow. The divider circuit was synthesized on a Philbrick-Nexus RP-E operational manifold utilizing model P85AU operational amplifiers (Analog Devices, Inc., Cambridge, Mass.) and a model 4450 analogue multiplier connected to yield the desired quotient. Additional op- erational amplifiers provided the required interface voltage offset and scaling functions. A Beckman model 9857B cardiotachometer triggered by the instantaneous pressure signal, was used to compute heart rate on beat-by-beat basis.

\section{RESULTS}

Heart rate. In the normal dogs, heart rate increased from a reclining resting value of $84 \pm 3 \mathrm{sEM}$ beats/min to $259 \pm 6$ beats/min during severe exercise (Fig. 2). The increase in heart rate was abrupt (Figs. 3-5) and began with the anticipation of exercise. Heart rate remained at peak levels as long as the dogs did not decrease their level of exercise or stop to urinate or defecate (Figs. 3-5). At the cessation of exercise, heart rate abruptly decreased but remained elevated above control and then gradually returned to preexercise control levels during the subsequent $45 \mathrm{~min}$.

In dogs with complete heart block-resting heart rate, $47 \pm 1$ beats/min, which was significantly lower then the resting heart rate in these dogs before heart block $(P<$ 0.001 ), increased gradually during severe exercise to 78 \pm 3 beats $/ \mathrm{min}$. Most runs were punctuated by occasional premature contractions and by occasional short runs of tachycardia when the dogs appeared near exhaustion. After exercise, heart rate gradually returned to preexercise control levels during the subsequent 45 $\min$.

Arterial pressure. In the normal dogs, arterial pressure uniformly increased during severe exercise after an initial brief decrease observed in some dogs. Mean pressure increased from an average reclining resting

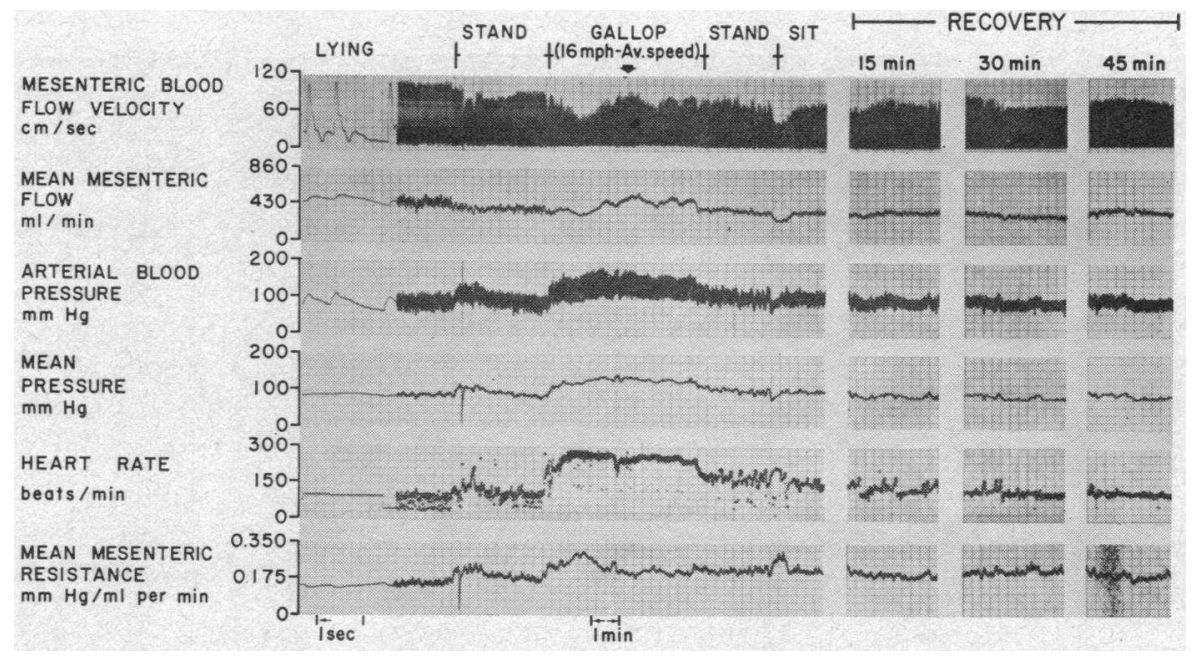

FIGURE 3 Record from a normal dog reclining at rest, then standing, then running at an average speed of $16 \mathrm{miles} / \mathrm{hr}$, and the subsequent recovery from exercise 15,30 , and 45 min later. This record shows phasic waveforms and mean values for mesenteric blood flow and arterial blood pressure, heart rate, and computed mean mesenteric flow resistance. The arrow points to a short interval where the dog paused to defecate. The slight initial decrease in mesenteric flow at the beginning of exercise represented as great a reduction in visceral flow as occurred with severe exercise in the normal dogs. 


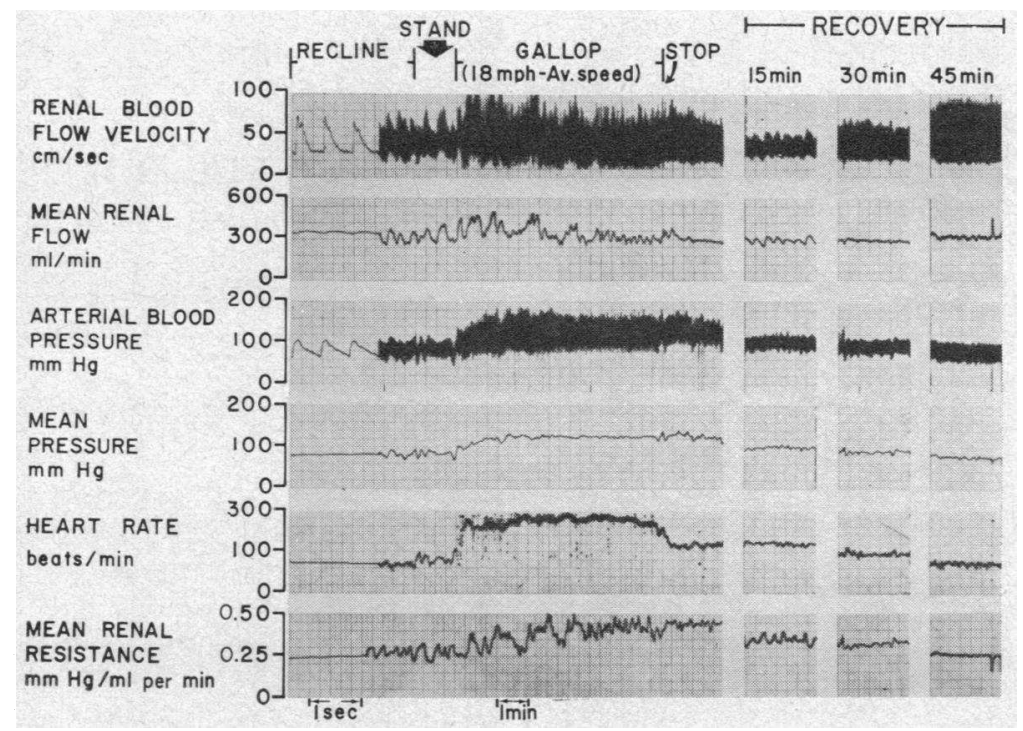

FIGURE 4 Record from a normal dog reclining, then standing, then running at an average speed of $18 \mathrm{miles} / \mathrm{hr}$, and the subsequent recovery from exercise immediately and at 15,30 , and 45 min later. The phasic waveforms and mean values for renal blood flow and arterial pressure, heart rate, and computed mean renal resistance are shown. In this case renal blood flow actually increased slightly during severe exercise.

value of $89 \pm 4$ to $140 \pm 5 \mathrm{~mm} \mathrm{Hg}$ during severe exercise (Fig. 2). In contrast with the response of heart rate, the increase in pressure occurred gradually and was often not observed until after the 1st min of severe exercise. Pressure remained elevated at a generally constant value as long as the dogs did not decrease their level of exer- cise (Figs. 3-5). During recovery from exercise pressure gradually returned to preexercise control values during the subsequent 45 min.

In six dogs with complete heart block, reclining at rest, mean arterial pressure was $81 \pm 3 \mathrm{~mm} \mathrm{Hg}$ as compared with $89 \pm 4 \mathrm{~mm} \mathrm{Hg}$ for the normal dogs. The

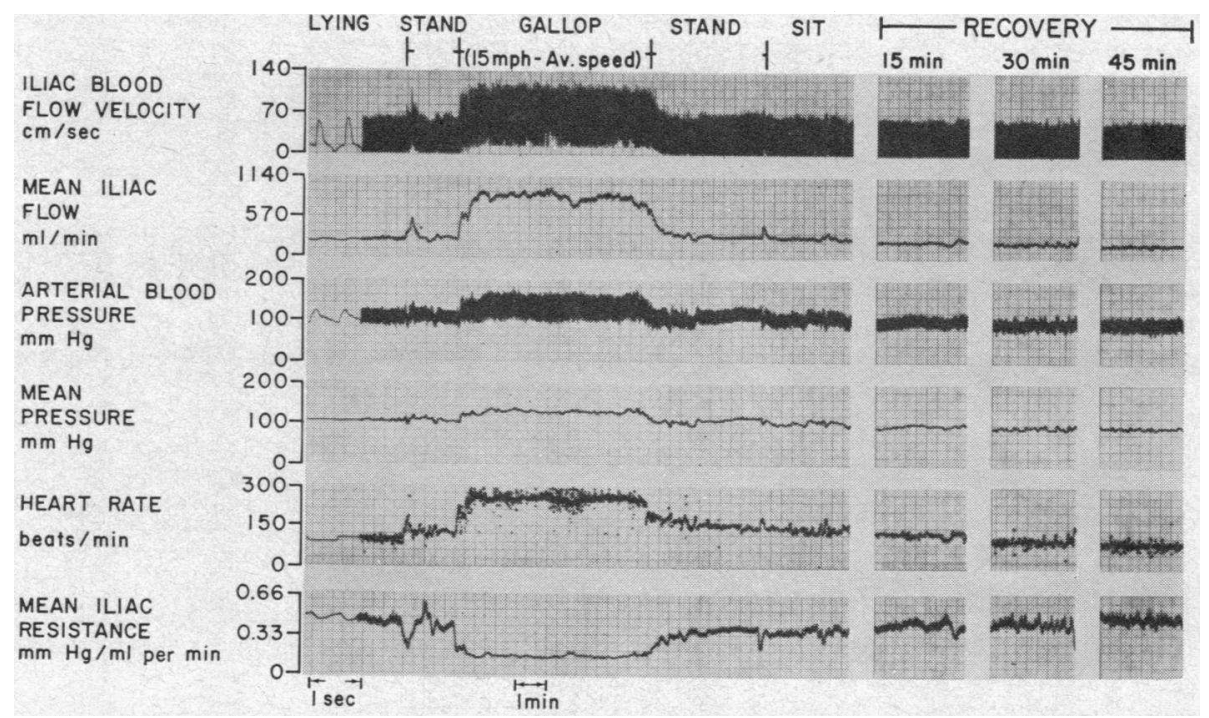

FIgURE 5 Record from a normal dog reclining, then standing, then running at an average speed of $15 \mathrm{miles} / \mathrm{hr}$ and the subsequent recovery from exercise immediately and at 15, 30, 45 min later. The phasic waveforms and mean values from iliac blood flow and arterial pressure, heart rate, and computed mean iliac resistance are shown. 


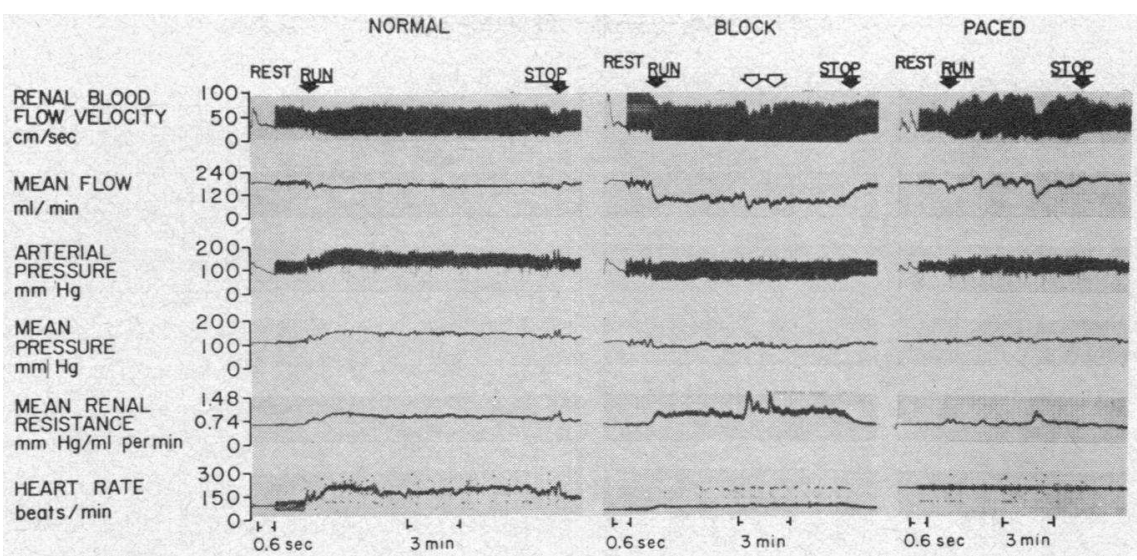

FIgURE 6 A comparison of the response to exercise of phasic and mean renal blood flow and arterial pressure, computed mean renal flow resistance, and heart rate in the same dog running before block (left panel), 2 wk later running after induced heart block (middle panel) and running paced at a ventricular rate of $200 / \mathrm{min}$ (right panel). There are occasional mistriggerings of the cardiotachometer in the panel at the left and at the right, but not in the middle panel which shows the extrasystoles that occur during exercise in heart block. In the middle panel the arrows point to two brief instances where renal flow approached zero when the dog altered course to chase squirrels.

resting mean arterial pressure was significantly lower in the heart block dogs $(P<0.01)$. In dogs with heart block, the pulse pressure was considerably widened. The onset of exercise in these dogs was generally characterized by an initial fall in arterial pressure which was greater in magnitude and more prolonged than in the normal dogs. Also in contrast with the normals, in three dogs, pressure did not increase during exercise and in two of these dogs, pressure decreased and remained depressed (Figs. 6, 7). Mean pressure at rest $81 \pm 3 \mathrm{~mm}$ $\mathrm{Hg}$ did not increase significantly $(P>0.5)$ during severe exercise $89 \pm 4 \mathrm{~mm} \mathrm{Hg}$ (Fig. 2). The difference between the normal response of arterial pressure to exercise and the response in heart block was significant $(P<0.01)$. Similar results occurred when heart rate was held constant during exercise by electrically pacing the ventricles at $100 / \mathrm{min}$. When the heart was held constant at $200 / \mathrm{min}$, the increase in mean arterial pressure from 91 to $112 \mathrm{~mm} \mathrm{Hg}$ with severe exercise was greater than that observed when the dogs ran in heart block, but was not as great as in the normal dogs.

Mesenteric and renal beds. In normal dogs, mesenteric and renal blood flows remained constant during severe exercise (Fig. 2). Mesenteric blood flow was within $1 \pm 3 \%$ of preexercise control (average $=432 \mathrm{ml} / \mathrm{min}$ ) while renal flow was $3 \pm 3 \%$ above preexercise control (average $=287 \mathrm{ml} / \mathrm{min}$ ). In some cases, an initial decrease in mesenteric or renal flow occurred at the onset of exercise but blood flow returned to control levels during exercise (Fig. 3) and in some cases rose above control during severe exercise (Fig. 4). Resistance in the mesenteric and renal beds uniformly increased with severe exercise; by an average of $59 \pm 7 \%$ in the mesenteric bed (from a control of $0.185 \mathrm{~mm} \mathrm{Hg} \mathrm{ml} / \mathrm{min}$ ) and by an average of $52 \pm 7 \%$ in the renal bed (from a control of $0.310 \mathrm{~mm} \mathrm{Hg} / \mathrm{ml}$ per $\mathrm{min}$ ). Since blood flow remained relatively constant, the increase in vascular resistance was proportional to the increase in arterial pressure. Resistance in these beds remained elevated during recovery from exercise and gradually returned to preexercise control levels over the subsequent $45 \mathrm{~min}$ during recovery. In some instances, a transient increase in renal or mesenteric blood flow occurred at the ces-

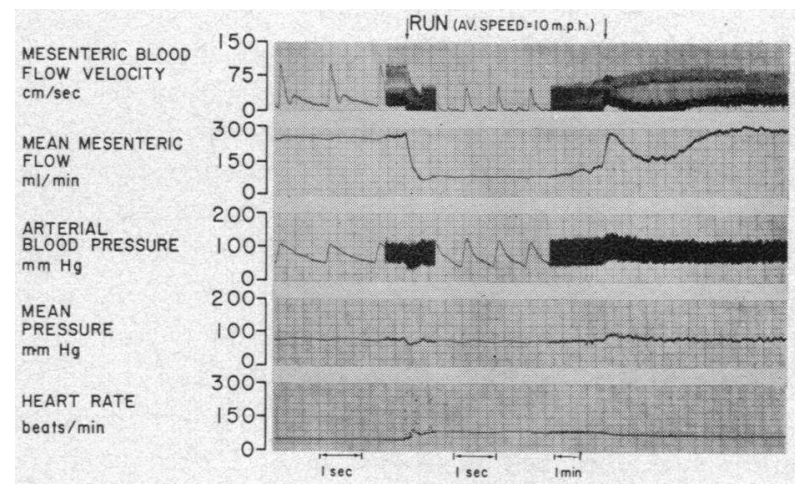

Figure 7 A continuous record from one of the dogs in heart block at rest and then running at an average speed of $10 \mathrm{miles} / \mathrm{hr}$. The phasic waveform of mesenteric flow and arterial pressure at fast paper speed during exercise (center) can be compared with the waveforms at rest before exercise (left). 


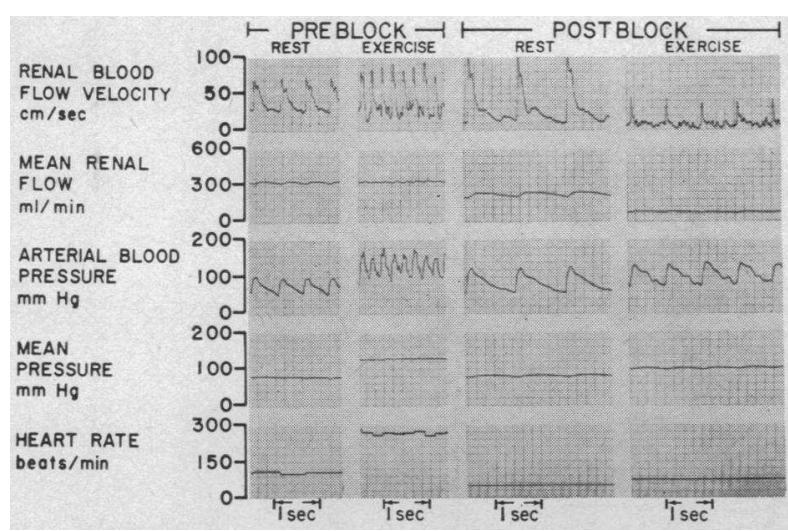

Figure 8 A comparison between rest and severe exercise oi the phasic waveforms and mean values of renal blood flow and arterial pressure at fast paper speed for a dog that exercised before and after heart block. Note that during exercise before heart block (left panels) arterial pressure increased significantly but renal blood flow did not decrease, while in heart block (right panels) the increase in pressure was much less and renal blood flow decreased significantly.

sation of exercise, but since pressure declined slowly from its elevated levels there was still an elevation in calculated resistance above preexercise control.

In the dogs with complete heart block, renal and mesenteric flow decreased during severe exercise and remained depressed as long as the dogs continued to run at speeds of over $10 \mathrm{miles} / \mathrm{hr}$ (Figs. 6, 7). Mesenteric blood flow decreased by $61 \pm 6 \%$ of preexercise control levels (from 315 to $123 \mathrm{ml} / \mathrm{min}$ ) (Fig. 7) and renal flow decreased by $65 \pm 7 \%$ (from 253 to $89 \mathrm{ml} / \mathrm{min}$ ). These responses to severe exercise were significantly different from those before heart block $(P<0.001)$. The decrease in flow during severe exercise in the renal and mesenteric beds occurred during both systole and diastole (Figs. $7,8)$. Diastolic flow in both beds approached zero and in some cases reverse flow may have occurred. Since the demodulation scheme in the Doppler device used in this study does not sense reverse flow, ngeative flow is recorded as positive. This would tend to underestimate the magnitude of the decrease in mesenteric and renal flow during severe exercise in the heart block dogs. When these dogs failed to continue to exercise severely and ran at speeds of less than $10 \mathrm{miles} / \mathrm{hr}$ the responses of mesenteric and renal blood were variable and equivocal.

During severe exercise, calculated resistance increased in the mesenteric bed by an average of $222 \pm 19 \%$ above a control of $0.257 \mathrm{~mm} \mathrm{Hg} / \mathrm{ml}$ per min and in the renal bed by an average of $273 \pm 31 \%$ above a control of 0.320 $\mathrm{mm} \mathrm{Hg} / \mathrm{ml}$ per min. The increases in mesenteric and renal resistance during exercise were significantly greater $(P<0.01)$ in the dogs with heart block. Blood flow and resistance returned to control levels within $45 \mathrm{~min}$ after exercise ceased. Similar results occurred when the three dogs in AV block were exercised at a ventricular rate of $100 / \mathrm{min}$. However, when these dogs exercised while being paced at $200 / \mathrm{min}$, a more normal response reappeared (Fig. 6). In these instances, mesenteric blood flow decreased to an average of $73 \%$ of preexercise control, while renal flow decreased to an average of $77 \%$ of preexercise control. Calculated resistance increased by an average of $53 \%$ above control in the mesenteric bed and resistance was $43 \%$ above control in the renal bed.

Iliac bed. Iliac blood flow increased promptly with severe exercise (Fig. 5), the increase in blood flow being roughly proportional to the severity of the exercise. In normal dogs, iliac blood flow increased by an average of $479 \pm 25 \%$ above control from 189 to $969 \mathrm{ml} / \mathrm{min}$, while iliac resistance declined by $73 \pm 1 \%$ from a control of $0.484 \mathrm{~mm} \mathrm{Hg} / \mathrm{ml}$ per min. With the cessation of exercise iliac flow declined abruptly at first and then gradually decreased to preexercise control levels over the subsequent $45 \mathrm{~min}$.

In the dogs with heart block, iliac flow increased significantly less $(P<0.001)$, by only $221 \pm 1 \%$ above control, (from 128 to $411 \mathrm{ml} / \mathrm{min}$ ) while resistance decreased less as well $(P<0.05)$, by only $62 \pm 3 \%$ value of from an average resting $0.633 \mathrm{~mm} \mathrm{Hg} / \mathrm{ml}$ per min. In the dogs paced at a rate of $100 / \mathrm{min}$ similar results occurred but when paced at $200 / \mathrm{min}$, iliac flow increased to $383 \%$ above control and resistance decreased by $74 \%$.

\section{DISCUSSION}

The cardiovascular response to exercise involves several compensatory mechanisms to satisfy the increased metabolic requirements of the exercising muscles. On the one hand there is an increased arteriovenous oxygen extraction and a shift in metabolism occurs resulting in increased anaerobic metabolism and lactate production $(15,16)$. In addition, the resistance to blood flow in the exercising limbs is greatly reduced, resulting in an augmentation of muscle blood flow. To meet the increased blood flow requirements of the working muscles, significant compensatory adjustments during exercise are known to occur in the heart resulting in an increase in cardiac output, which occurs mainly through increases in heart rate and to a lesser extent through increases in stroke volume $(17,18)$.

In addition to these well-known adjustments to exercise, a second compensatory mechanism involving sufficient increases in visceral vascular resistances to reduce visceral blood flow is thought to occur (1-8). The early experimental basis for this concept was derived from studies in humans, observing altered renal function, i.e., proteinuria and oliguria with exercise and indicating 
that renal arterial vasoconstriction occurred $(19,20)$. Exteriorized colons were observed to blanch during exercise and spleens of dogs were observed to decrease in size, suggesting splanchnic vasoconstriction $(21,22)$. It is of interest that the blanching of the colon was transient and color returned to control during exercise and a similar pattern of a transient initial decrease in mesenteric or renal blood flow was observed in some of the animals in the present study (Fig. 4). Further support for the theory that visceral flow decreased during exercise came from studies in anesthetized animals showing that stimulation of sympathetic nerves to the mesenteric and renal vessels or the infusion of catecholamines decreased mesenteric and renal blood flows $(23,24)$. Other studies in anesthetized animals in which exercise was simulated, confirmed the reductions in visceral flows $(8,25-27)$. In addition, several investigations utilizing indirect techniques for measuring regional blood flow have indicated that in normal man, renal and splanchnic blood flows decrease with exercise and that the reduction in flow was roughly proportional to the severity of the exercise (1-7). Considering the weight of this evidence in combination with the teleological attractiveness of an efficient mechanism for shunting of superfluous visceral flow to the exercising musculature, it is not surprising that the hypothesis of visceral shunting during exercise has assumed the proportions of a law.

However, direct measurements of renal and mesenteric blood flow in intact, conscious dogs during exercise indicated that renal and mesenteric blood flows did not decrease during exercise (9-11). These investigations showed that although flow to the hindlimb increased by as much as 12 -fold, mesenteric and renal blood flows remained relatively constant. The earlier studies utilizing treadmill exercise $(9,10)$ were criticized on the bases that the level of exercise attained was not severe enough and that shunting of blood flow occurrd only during severe stress. To resolve this controversy, Van Citters and Franklin studied the responses of Alaskan sled dogs running long distances in subzero temperatures while pulling a sled (11). Even under such extreme circumstances to the point of prostration, mesenteric and renal blood flows did not decrease. Criticism of this study was directed to the use of sled dogs, which are unusual animals, specially adapted through training and breeding for exercise and thus might not show the compensatory shunting of visceral blood flow (27).

In the present investigation, measurements of mesenteric, renal and iliac blood flows, and aortic blood pressure were telemetered from 11 normal, healthy, untrained mongrel dogs while they ran spontaneously behind a mobile recording unit for distance averaging 1.5 miles and ranging up to 6 miles at speeds of $15-25 \mathrm{miles} / \mathrm{hr}$. The dogs required $45 \mathrm{~min}$ of rest for cardiovascular and res- piratory function to recover from this degree of exercise. In these dogs, heart rate increased from 89 to $259 / \mathrm{min}$ and iliac blood flow from 189 to $969 \mathrm{ml} / \mathrm{min}$. In other words, we measured peripheral blood flows and pressures in normal, untrained animals as they exercised spontaneously at what may be reasonably considered "vigorous" and perhaps near maximum work loads. Renal and mesenteric blood flows remained at preexercise control levels during steady state severe exercise. Thus, we conclude that in normal, healthy mongrel dogs, the peripheral vascular response to severe exercise does not involve a compensatory reduction of visceral blood flow as specifically indicated by mesenteric and renal arterial blood flows. In this regard these findings are in agreement with the eariler stuides utilizing treadmill exercise $(9,10)$ and the findings of Van Citters and Franklin in Alaskan sled dogs (11). Our findings do not support the conclusions of previous investigations of visceral flow during simulated exercise in anesthetized preparations $(8,25-27)$ or the prior studies in conscious humans (1-7) which suggested that marked reductions in visceral blood flows occurred. The differences between our findings and those in anesthetized preparations may be explained on the basis of the inherent difficulties of studying exercise, a function intrinsically peculiar to intact, conscious organisms and difficult to simulate in anesthetized animals lying on the surgical table. The differences between our findings and those in conscious humans are more difficult to explain and may be due either to differences in species or in instrumentation. Measurements of blood flow in conscious humans are necessarily indirect, whereas in our studies, blood flow transducers are applied directly to the renal, mesenteric, and iliac arteries. There is yet another explanation for the discrepancy between our findings and the studies in humans. The paraminohippurate clearance technique which has been employed to measure renal plasma flow would not sense renal arteriovenous shunting or redistribution of flow within the kidney (28). In fact, Selkurt has pointed out discrepancies as great as $60 \%$ between directly measured renal flow and calculated renal flow from paraminohippurate clearance $(29,30)$. Thus, during exercise, flow to the glomerular capillaries, which the paraminohippurate technique measures, could decrease without a concomitant decrease in renal arterial inflow. And finally, when using methods that do not measure blood flow continuously, there is the possibility that visceral flow might have been sampled at one point when it was transiently decreased. As mentioned previously initial transient decreases in mesenteric or renal blood flow during exercise were observed in some of the animals (Fig. 4).

While the indirect methods of measuring regional blood flow in conscious humans may not record ar- 
terial inflow as accurately as implanted flowmeters, the instrumentation employed in this investigation is also liable to error. First the demodulation scheme in the ultrasonic Doppler device employed in this study does not sense reverse flow. Thus, it is conceivable that during exercise a decrease in renal or mesenteric flow would not be detected if significant reverse flow occurred. This is probably not the case for two reasons. First, earlier studies measuring visceral flows during treadmill exercise with directional flowmeters indicated that significant negative blood flow did not occur $(10,31)$. Secondly, reverse flow would most likely occur during diastole and when flow decreased strikingly during exercise in the dogs with heart block, forward or reverse flow during diastole was negligible. Another limitation of the Doppler device is that the Doppler shift is proportional to blood velocity and should the cross sectional area of the vessel within the transducer decrease, blood velocity would not decrease linearly with volume flow. This also is probably not a source of error in the present experiments for several reasons. First the vessels in these animals were observed at autopsy to be fixed to the transducers through a fibrous scar which would minimize changes in vessel diameter. Secondly, the pressure during exercise increased which would act to prevent a decrease in vessel diameter. Thirdly, simultaneous measurements with electromagnetic and ultrasonic Doppler flowmeters of peripheral blood flows in conscious animals at rest and during exercise have shown both instruments to accurately record changes in volume flow (14). Finally, in the present investigation, significant reductions in visceral flow were recorded when utilizing the same instrumentation for the same dogs exercising in heart block.

Although the peripheral vascular response to severe exercise in normal dogs does not involve a reduction in visceral flow, in the present study significant increases in renal and mesenteric resistances $(P<0.001)$ were observed. In the normal dogs, arterial pressure increased from an average of 89 to $140 \mathrm{~mm} \mathrm{Hg}$. Since blood flow to the gut and kidney remained constant, the increases in mesenteric and renal resistance paralleled the increases observed in arterial blood pressure. This finding was also observed in the studies by Herrick, Grindlay, Baldes, and Mann (9) and Essex, Herrick, Baldes, and Mann (32). However, Rushmer, Franklin, Van Citters, and Smith (10) and Van Citters and Franklin (11) did not report increases in arterial pressure and visceral resistance. In the present study, the magnitude of the increase in arterial pressure appeared to be roughly related to the severity of exercise.

In contrast with the normal dogs, the dogs with complete heart block increased heart rate only from 47 to $78 / \mathrm{min}$. The increase in heart rate was different from the normal response not only being significantly less in magnitude $(P<0.001)$ but also in the manner in which it occurred. In the normal dogs as has been repeatedly observed, heart rate increased abruptly. In the dogs with complete heart block heart rate increased gradually. The abrupt increase in heart rate in the normal dogs is to a great extent due to withdrawal of vagal inhibition on the sinus pacemaker whereas the increase in ventricular rate in heart block dogs mainly evolves from increased sympathetic drive to the ventricles due to neural influences and circulating catecholamines. A similar gradual increase in heart rate during exercise was observed by Donald and Shepherd in dogs with denervated hearts $(33,34)$.

Another difference between the dogs before and after heart block was in the response of arterial pressure. As noted above, the normal dogs increased arterial pressure from 89 to $140 \mathrm{~mm} \mathrm{Hg}$, whereas the heart block dogs increased arterial pressure only from 81 to $89 \mathrm{~mm} \mathrm{Hg}$. This difference in the response of arterial pressure to severe exercise was significant $(P<0.01)$. Since the visceral vasoconstriction was more intense in the dogs with heart block, the explanation for the smaller rise in blood pressure must be derived from other factors. First the level of exercise attained by the heart block dogs was less and as noted previously in the normal dogs the increase in pressure was roughly proportional to the severity of exercise. Since the arterial pressure depends on the relationship between peripheral resistance and the cardiac output and since visceral vasoconstriction was augmented during exercise in heart block, the diminished pressor response must have been due to the lesser increase in cardiac output. This hypothesis is supported by the finding that iliac blood flow increased to 969 $\mathrm{ml} / \mathrm{min}$ in normal dogs during exercise, but to only 411 $\mathrm{ml} / \mathrm{min}$ in dogs with heart block. The hypothesis that cardiac output does not increase appropriately during severe exercise conflicts with the conclusion of previous investigations on the response to exercise in man and dogs with heart block and without myocardial disease (35-38). However, in the latter studies the level of exercise was significantly less. The most severe exercise in these studies was obtained by Hopkinson, Chardack, Heyden, and Schenk (38), dogs running at 7.5 m.p.h. on a treadmill with a $10 \%$ grade. It is possible that with exercise comparable with that attained in the present study, in the absence of a normal heart rate response, stroke volume could not adequately compensate and cardiac output did not increase appropriately.

Another significant difference from the normal response occurred in the visceral beds. During severe exercise, mesenteric and renal blood flows decreased to 39 and $35 \%$ of preexercise control respectively. Thus a compensatory reduction of visceral flow occurred. In these dogs diversion of blood flow from the inactive vis- 
cera to the exercising muscle may have been necessary since the normal four- to fivefold increase in cardiac output that occurs with exercise could not be achieved when the increase in heart rate was limited. It is significant that despite the fact that the degree of severity of exercise was less in the dogs after heart block had been induced, reduction of visceral flow occurred, whereas in the same dogs before heart block visceral flows were maintained during exercise. Although the normal dogs ran at greater speeds, the degree of stress to the circulation was probably greater in the dogs with heart block. In some instances renal and mesenteric blood flows decreased by as much as $90 \%$ from preexercise control levels during severe exercise in dogs with heart block. Maintaining heart rate constant with electrical pacing at a ventricular rate of $100 / \mathrm{min}$ also resulted in similar reductions in visceral flow during severe exercise. However, when these dogs were paced at a ventricular rate of $200 / \mathrm{min}$, they were able to increase their level of exercise and arterial pressure increased but the reduction in visceral blood flow became less apparent. This indicates that the major difference in the response to severe exercise between the dogs before and after heart block was the inability to increase heart rate and differences due to the additional surgery or failure on a myocardial basis probably played less significant roles.

It could be argued that the increases in calculated resistance to the mesenteric and renal beds in the normal dogs underestimated the vasomotor changes in these beds. Since the relationship between pressure and flow in peripheral beds is curvilinear (39) the increase in pressure observed in the present experiments might have been expected to cause flow to increase to an even greater extent than pressure did if sympathetic vasoconstriction or autoregulatory mechanisms were not acting in the opposite direction. In addition to the increased pressure there are other possible mechanisms that would tend to maintain renal and mesenteric blood flow in the normal dogs during severe exercise. First, the increase in arterial pressure would activate the baroreceptor reflexes to counteract increases in resistance. Previous studies have shown that baroreceptor activation causes renal and mesenteric vasodilatation in conscious dogs at rest and during exercise (40). Secondly, autoregulation of blood flow in the renal and mesenteric beds has been demonstrated $(23,24)$ and this mechanism would tend to maintain blood flow to the gut and kidney. In the dogs with heart block during severe exercise, pressure did not increase significantly which should have resulted in less baroreceptor mediated vasodilatation and, in fact, the reverse may have occurred, i.e., the baroreceptors may have played a role in the development of the intense visceral vasoconstriction to help maintain pressure. Clearly autoregulatory mechanisms were not sufficiently powerful to maintain blood flow and, thus, renal and mesenteric blood flows decreased significantly and remained depressed.

Thus, the peripheral vascular response to severe exercise in normal untrained healthy dogs involves an increase in renal and mesenteric vascular resistances, but blood flow to the kidney and gut are maintained. Although the fraction of cardiac output to the kidney and gut decreases during exercise a redistribution of blood flow involving a compromise in these circulations does not occur. During severe exercise in dogs with complete heart block the increases in visceral resistance are greater and visceral flows are reduced and in this situation a true shunting of blood flow occurs, i.e., blood flow to the viscera decreased to provide blood flow for the exercising muscles. This study indicates that the mechanism by which blood flow can be diverted from the viscera exists in the normal animal but is not utilized as long as the augmentation of cardiac output can satisfy the increased metabolic requirements of the exercising musculature. When a primary compensatory mechanism in the response to exercise is inadequate, e.g., the increase in heart rate, a secondary mechanism is utilized, e.g., reduction of visceral blood flow.

\section{ACKNOWLEDGMENTS}

We wish to acknowledge the electrical pacemaker from Medtronic, Inc. and are grateful for encouragement and advice from Dr. Robert L. Van Citters and Dr. Eugene Braunwald.

This work was supported by U. S. Public Health Service Grants HE 12373 and HE 13441.

\section{REFERENCES}

1. Chapman, C. B., A. Henschel, J. Minckler, A. Forsgren, and A. Keys. 1948. The effect of exercise on renal plasma flow in normal male subjects. J. Clin. Invest. 27 : 639.

2. White, H. L., and D. Rolf. 1948. Effects of exercise and of some other influences on the renal circulation in man. Amer. J. Physiol. 152: 505.

3. Bucht, H., J. Ek, H. Eliasch, A. Holmgren, B. Josephson, and L. Werko. 1953. The effect of exercise in the recumbent position on the renal circulation and sodium excretion in normal individuals. Acta Physiol. Scand. 28: 95.

4. Harpuder, K., M. Lowenthal, and S. Blatt. 1957. Peripheral and visceral vascular effects of exercise in the erect position. J. Appl. Physiol. 11: 185.

5. Wade, O. L., B. Combes, A. W. Childs, H. O. Wheeler, A. Cournand, and S. E. Bradley. 1956. The effect of exercise on the splanchnic blood flow and splanchnic blood volume in normal man. Clin. Sci. 15: 457.

6. Rowell, L. B., J. R. Blackmon, and R. A. Bruce. 1964. Indocyanine green clearance and estimated hepatic blood flow during mild to maximal exercise in upright man. J. Clin. Invest. 43: 1677.

7. Wade, O. L., and J. M. Bishop. 1962. The distribution of cardiac output in normal subjects during exercise. 
In Cardiac Output and Regional Blood Flow. Blackwell Scientific Publication, Oxford. 95.

8. Best, C. H., and N. B. Taylor. 1961. The output of the heart and the regulation of its action. In The Physiological Basis of Medical Practice. The Williams \& Wilkins Co., Baltimore. 302.

9. Herrick, J. F., J. H. Grindlay, E. J. Baldes, and F. C. Mann. 1939. Effect of exercise on the blood flow in the superior mesenteric, renal and common iliac arteries. Amer. J. Physiol. 128: 338.

10. Rushmer, R. F., D. L. Franklin, R. L. Van Citters, and O. A. Smith. 1961. Changes in peripheral blood flow distribution in healthy dogs. Circ. Res. 9: 675.

11. Van Citters, R. L., and D. L. Franklin. 1969. Cardiovascular performance of Alaska sled dogs during exercise. Circ. Res. 24: 33.

12. Franklin, D. L., N. W. Watson, K. E. Pierson, and R. L. Van Citters. 1966. A technique for radiotelemetry of blood flow velocity from unrestrained animals. Amer. J. Med. Electron. 5 : 24.

13. Van Citters, R. L., and D. L. Franklin. 1966. Telemetry of blood pressure in free-ranging animals via an intravascular gauge. J. Appl. Physiol. 21: 1633.

14. Vatner, S. F., D. Franklin, and R. L. Van Citters. 1970. Simultaneous comparison and calibration of the Doppler and electromagnetic flowmeters. J. Appl. Physiol. 29: 907.

15. Barger, A. C., V. Richards, J. Metcalfe, and B. Günther. 1956. Regulation of the circulation during exercise. Cardiac output (Direct Fick) and metabolic adjustments in the normal dog. Amer. J. Physiol. 184: 613.

16. Barcroft, H. 1963. Circulation in skeletal muscle. In Handbook of Physiology. Circulation. W. F. Hamilton and P. Dow, editors. The Williams \& Wilkins Co, Baltimor. 11: 1353.

17. Rushmer, R. F. 1959. Constancy of stroke volume in ventricular responses to exertion. Amer. J. Physiol. 196: 745.

18. Franklin, D. L., R. M. Ellis, and R. F. Rushmer. 1959. Aortic blood flow in dogs during treadmill exercise. $J$. Appl. Physiol. 14: 809.

19. Collier, W. Functional albuminuria in athletes. 1907. Brit. Med.J. $1: 4$.

20. MacKeith, N. W., M. S. Pembrey, W. R. Spurrell, E. C. Warner, and H. J. W. J. Westlake. 1923. Observations on the adjustment of the human body to muscular work. Proc. Roy Soc. London. Ser. B. 95: 413.

21. Barcroft, J., H. A. Harris, D. Orahovats, and R. Weiss. 1925. A contribution to the physiology of the spleen. J. Physiol. (London). 60 : 443.

22. Barcroft, J., and H. Florey. 1929. The effects of exercise on the vascular conditions in the spleen and colon. $J$. Physiol. (London). 68: 181.

23. Selkurt, E. E. 1963. The renal circulation. In Handbook of Physiology. Circulation. W. F. Hamilton and P. Dow, editors. The Williams \& Wilkins Co., Baltimore. 2: 1457.

24. Grim, E. 1963. The flow of blood in the mesenteric vessels. In Handbook of Physiology. Circulation. W. F. Hamilton and P. Dow, editors. The Williams \& Wilkins Co., Baltimore. 2: 1439.
25. Krogh, A. 1912. The regulation of the supply of blood to the right heart with a description of a new circulation model.) Skand. Arch. Physiol. $27: 227$.

26. Green, H. D., and E. C. Hoff. 1937. Effects of faradic stimulation of the cerebral cortex on limb and renal volumes in the cat and monkey. Amer. J. Physiol. 118: 641.

27. Wexler, I., and F. F. Kao. 1970. Neural and humoral factors affecting canine renal blood during induced muscular work. Amer. J. Physiol. 218: 755.

28. Trueta, J., A. E. Barclay, P. M. Daniel, K. J. Franklin, and M. M. L. Prichard. 1947. In Studies of the Renal Circulation. Blackwell Scientific Publications, Oxford. 187.

29. Selkurt, E. E. 1946. Comparison of renal clearances with direct renal blood flow under control conditions and following renal ischemia. Amer. J. Physiol. 145: 376.

30. Selkurt, E. E. 1946. Renal blood flow and renal clearance during hemorrhagic shock. Amer. J. Physiol. 145: 699.

31. Vatner, S. F., D. Franklin, and R. L. Van Citters. 1970. Mesenteric vasoactivity associated with eating and digestion in the conscious dog. Amer. J. Physiol. 219: 170.

32. Essex, H. E., J. F. Herrick, E. J. Baldes, and F. C. Mann. 1939. Influence of exercise on blood pressure, pulse rate and coronary blood flow of the dog. Amer. J. Physiol. 125: 614.

33. Donald, D. E., S. E. Milburn, and J. T. Shepherd. 1964 Effect of cardiac denervation on the maximal capacity for exercise in the racing greyhound. J. Appl. Physiol. 19: 849.

34. Donald, D. E., and J. T. Shepherd. 1964. Initial cardiovascular adjustment to exercise in dogs with chronic cardiac denervation. Amer. J. Physiol. 207: 1325.

35. Holmgren, A., P. Karlberg, and B. Pernow. 1959. Circulatory adaptation at rest and during muscular work in patients with complete heart block. Acta Med. Scand. 164: 119.

36. Warner, H. R., and A. F. Toronto. 1960. Regulation of cardiac output through stroke volume. Circ. Res. 8: 549.

37. McGregor, M., and G. A. Klassen. 1964. Observations on the effect of heart rate on cardiac output in patients with complete heart block at rest and during exercise. Circ. Res. II (Suppl.): 215.

38. Hopkinson, B. R., W. M. Chardack, W. C. Heyden, and W. G. Schenk, Jr. 1970. Response of cardiac output to severe exercise of dogs in complete heart block with and without artificial pacing. J. Thorac. Cardiovasc. Surg. 59: 733 .

39. Green, H. D., C. E. Rapela, and M. C. Conrad. 1963. Resistance (conductance) and capacitance phenomena in terminal vascular beds. In Handbook of Physiology. Circulation. W. F. Hamilton and P. Dow, editors. The Williams \& Wilkins Co., Baltimore. 2: 935.

40. Vatner, S. F., D. Franklin, R. L. Van Citters, and E. Braunwald. 1970. Effects of carotid sinus nerve stimulation on blood-flow distribution in conscious dogs at rest and during exercise. Circ. Res. 27: 495. 